\title{
Aeromagnetic characterization of parts of Ondo and Ekiti States, Southwestern Nigeria
}

\author{
Omowumi Ademila \\ Department of Earth Sciences, Adekunle Ajasin University, Akungba Akoko +234, Nigeria \\ Email: omowumi.ademila@aaua.edu.ng
}

\begin{abstract}
Aeromagnetic data of Ikole Sheet 245 covering Ikole, Akoko and Kabba areas was studied with the aim of delineating subsurface geological structures towards detailed information on exploration, engineering construction and environmental assessment of the study area. The colour shaded Total Magnetic Intensity (TMI) was interpreted for anomalous zone, structural trends, lithological differentiation and closures. Reductions were made on Residual Field data produced. TMI map revealed high intensity amplitudes within $65-180 \mathrm{nT}$ representing crystalline and undeformed basement rocks, -150 to $-65 \mathrm{nT}$ for very low magnetic amplitudes representing infilled weathered and non-magnetic materials. Regional lineament trends diagonally from NE-SW dividing the map into equal halves, normal faults trending $\mathrm{N}-\mathrm{S}$ and a NW-SE trending ridge (intrusive granitic rock) between two large depressions in Akoko axis were seen on TMI map. The reduction to the equator (RTE) map showed that below lineament (Akoko to Kabba) and above lineament (Ikole) have high and low magnetic anomalies respectively. Upward continuation maps revealed rocks trend generally in NW-SE and identified structures as deep-seated. Tilt-angle Derivative (TDR) map showed extent of structures, NE-SW lineaments (R-R') and phases of N-S trending normal fault (F-F') to be over a wide area. The spectral depth analysis plot showed that shallow and deeper magnetic sources have an estimated depth of $140 \mathrm{~m}$ and $1.60 \mathrm{~km}$ respectively. This method has proved valuable in mapping basement structures and targeting suitable areas for groundwater exploration, metalliferous mineral deposits and delineates zones of faulting in bedrock of the study area.
\end{abstract}

Keywords: Aeromagnetic, Ikole Sheet, Magnetic Intensity, Geological Mapping, Depth to Magnetic Sources.

\section{INTRODUCTION}

Magnetic surveying investigates the subsurface based on the variation in the observed magnetic result from the differences in the magnetic properties of the underlying rocks, or in some cases cultural sources. A rock may be regarded as a heterogeneous assemblage of minerals of different matrixes (discrete grains of different sizes, shapes and colours), mainly silicates or carbonates which are diamagnetic in character and interspersed secondary minerals matrixes (such as the clay minerals) of lesser quantity that have paramagnetic properties. The bulk of the constituent minerals in a rock contributes to the magnetic susceptibility but is incapable of any contribution to the remanent magnetic properties, which are due to a dilute dispersion of ferromagnetic minerals. The variable concentrations of ferromagnetic and matrix minerals result in a wide range of susceptibilities in rocks. The weak and variable concentration of ferromagnetic minerals plays a key role in determining the magnetic properties of the rock that are significant geologically and geophysically. There are variations in the composition of magnetic properties within a rock type depending on chemical inhomogeneities, depositional and/or crystallization conditions and post deformational conditions, as well as their contributions in terms of mineral to the magnetic susceptibility of a rock. The values of magnetic susceptibility depend on the grain size, the presence of minute crystal lattice defects, such as dislocations, lattice vacancies, impurities etc. and the amount of iron ore in a sample [1, 2, 3]. Metamorphic and igneous rocks have greater magnetic properties (intensity and susceptibility) compared to sedimentary rocks which have low magnetic properties. Airborne magnetic surveys are useful to map geologic structure on or inside the basement rocks and to also detect magnetic minerals directly.

The magnetic method is a geophysical technique that measures variations in the earth's magnetic field to determine the location of subsurface features. The methodology for acquiring and compiling data appears to be keeping pace with modern technology so that presently the magnetic method is by far the most widely used of all geophysical survey. The largest airborne geophysical survey ever carried out in 
Nigeria, was conducted in three phases between 2005 and 2010 in order to position the country as an exciting destination for explorers. The recent survey has a Tie-line spacing of $500 \mathrm{~m}$, light line spacing of $100 \mathrm{~m}$, and terrain clearance of $100 \mathrm{~m}$ using TEMPEST system compared with the survey carried out in the 1970s which had a Tie-line spacing of $20 \mathrm{~km}$, light line spacing of $2 \mathrm{~km}$, and flying altitude of $200 \mathrm{~m} \mathrm{[4].}$

Aeromagnetic surveying is rapid and cost-effective, typically costing some $40 \%$ less per line kilometer than a ground survey. It is a significant tool in delineating the regional geology of buried basement terrain. This high resolution method is now being applied in groundwater, engineering and environmental studies [5], including the location of voids, near surface faults, igneous dikes and buried ferromagnetic objects etc. Magnetic field variations can be interpreted to determine an anomaly's depth, geometry and magnetic susceptibility. Recent advances in technology have considerably increased the accuracy and resolution of aeromagnetic technique in order to provide useful enhanced information on lithology and geological structures. Also, advances in data analysis, processing and image enhancement techniques have further improved the resolution of geophysical datasets so that very subtle variations in the geophysical responses can be identified [6]. Hence, this research is aimed at using aeromagnetic methods for determining the total magnetic field intensity; both surface and subsurface classification; geological and structural mapping of the study area using upward continuation and Tilt-angle derivative filters, and depth to magnetic sources estimation using spectral plot for the purpose of identification of suitable areas for groundwater exploration, mineral prospecting and construction of engineering works.

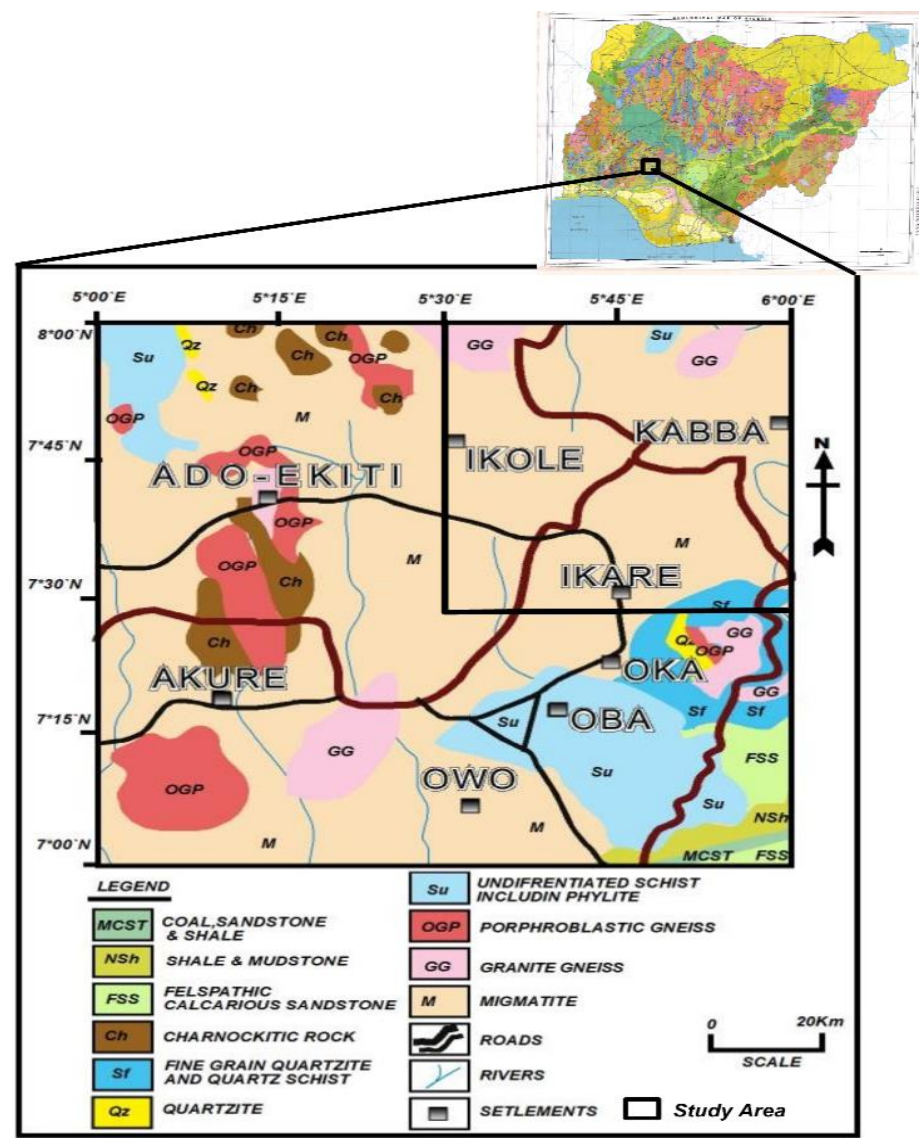

Figure 1. Geological map of the study area (adapted from Nigeria geological survey agency [15]

\section{GEOLOGIC SETTING OF THE STUDY AREA}

The study area (Ikole Sheet 245) lies within latitudes $7^{\circ}$ $30^{\prime} \mathrm{N}$ and $8^{\circ} 00^{\prime} \mathrm{N}$ and longitudes $5^{\circ} 30^{\prime} \mathrm{E}$ and $6^{\circ} 00^{\prime} \mathrm{E}$. It is divided into Ikole axis (Ekiti State), Akoko axis (Ondo State) and extends to Kabba (Kogi State) within the Southwestern Basement Complex of Nigeria. The Basement Complex rocks of Nigeria forms a part of the African crystalline shield which occurs within the Pan African mobile belt that lies between the West African and Congo Cratons and South of the Tuareg Shield which were affected by the Pan-African orogeny [7].

The Basement Complex of Southwestern Nigeria is located in a triangular portion of the Nigerian basement, an extension of the Dahomeyide shield of the West African Craton. Rocks of the region include Migmatized-Gneiss Complex (MGC) that is characterized by grey foliated gneiss, ultramafic rocks and felsic component comprised of pegmatite, aplite and granitic rocks [8]. The MGC in Southwestern Nigeria is affected by three major geotectonic events ranging from Early Proterozoic of 2000 Ma to Pan African events of $\sim 600$ Ma $[9,10,11]$. The rocks of the basement have been affected by medium pressure Barrovian metamorphism [11, 12]. The attitudes of tectonic structures in the Nigerian basement have been documented in terms of orientation and magma-induced veins and dykes such as quartz veins and pegmatites $[12,13]$. Deformation of the Nigerian basement complex occurred in two phases, a ductile phase, which is responsible for the formation of planar structures (foliations) and a brittle phase 
resulting in jointing and fractures, many of which have been filled with quartzo-feldspathic veins, dolerite dykes, pegmatite and aplitic veins and dykes [12].

The major lithological units include the migmatites, granite gneiss, charnockite, granite, and other felsic and mafic intrusives. The Basement rocks show great variations in grain size and in mineral composition. The rocks are predominantly quartz gneisses and schists consisting essentially of quartz with small amounts of white micaceous minerals. In grain size and structure, they vary from very coarse grained pegmatite to medium grained gneisses. The rocks of the basement complex in the area have been subjected to intense regional metamorphism resulting in the absence of minerals of high metamorphic grade. Magmatisation is widespread throughout the area reflected by rapid alternation of granite, biotite gneiss which grade into one another. Selective granitisation has resulted in biotite-rich layers in the gneisses being converted into porphyritic granite, while the leucocratic bands have been converted to aplitic granite. Minor folds are very common in the gneiss and schists and from all available evidence [14], the basic geological structure of Southwestern Nigeria is a complementary anticliriorium and synclinorium with northwards plunging axes.

\section{MATERIALS AND METHODS}

Total Magnetic Intensity (TMI) map (Aeromagnetic map) covering Ikole Sheet 245 (1:100 000) was acquired from Nigerian Geological Survey Agency (NGSA). Geosoft ${ }^{\circledR}$ Oasis Montaj ${ }^{\mathrm{TM}}$ software, Surfer and Microsoft Excel were used for data processing.

The TMI map (Aeromagnetic map) data is that of total field and is in a gridded form. This method fits minimum curvature curves (which is the smoothest possible surface that would fit the given data values) to data point using method described by [16]. Reduction of magnetic data is necessary to remove all causes of magnetic variation from the observations other than those arising from the magnetic effects of the subsurface. Other data reductions were carried out such as; the regional field of the area, residual of the data, reduction to magnetic equator, upward continuation (both coloured and the grey maps), tilt-angle derivative and its horizontal component, radial average power spectrum. The data reductions and corrections involve the followings:

3.1 Near Surface Noise (NSN) caused by metallic materials, fences, cables (both buried and surface) and others, which were not completely filtered out at data processing stage was the first process carried out on the TMI data acquired from NGSA.

3.2 The Regional Field (smoothed grid to $4 \mathrm{~km}$ ) of the data acquired was produced to deduce the Residual data (data we are interested in at this particular time) for the area covered. The Residual map is adopted as our new processed map with enhanced signal from the magnetic sources down depth. Other reductions were applied to the residual grid.

Residual $=$ Observed - Regional

3.3 The Reduction to Magnetic Equator (RTE) map was produced by using the RTE filter on the residual map.
To reduce the magnetic data to equator; equation 2 [17, 18] was applied to the data

$$
L(\theta)=\frac{[\sin (I)-i \cdot \cos (I) \cdot \cos (D-\theta)]^{2} \times\left(-\cos ^{2}(D-\theta)\right)}{\left[\sin ^{2}(I a)+\cos ^{2}(I a) \cdot \cos ^{2}(D-\theta)\right] \times\left[\sin ^{2}(I)+\cos ^{2}(I) \cdot \cos ^{2}(D-\theta)\right]}, \text { if }(|l a|<I D), I a=I
$$

where:

L $(\theta)=$ TMI Reduction to Equator (RTE)

$\mathrm{I}=$ geomagnetic inclination

$\mathrm{L}_{\mathrm{a}}=$ inclination for amplitude correction $($ never $<1$ )

$\mathrm{D}=$ geomagnetic declination

Reduction to the magnetic equator has an amplitude component (the sin (I) term) and a phase component ( i cos (I) $\cos (\mathrm{D}-\theta))$ component. When reducing to the equator from low latitudes, North-South features can blow-up due to the numerical error (from the term of $0 / 0$ ) in amplitude correction (the sin (I) component) that is applied when (D-) is ð/2 (i.e. a magnetic east-west wavenumber). By specifying higher latitude for the amplitude correction alone, this problem can be reduced or eliminated at the expense of slightly under-correcting the amplitudes of near North-South features. The following parameters calculated from geomagnetic calculator were used for RTE reduction;

Table 1. Parameters from geomagnetic calculator

\begin{tabular}{ccccccc}
\hline $\mathrm{D}\left({ }^{\circ}\right)$ & $\mathrm{I}\left(^{\circ}\right)$ & $\begin{array}{c}\mathrm{H} \\
(\mathrm{nT})\end{array}$ & $\begin{array}{c}\mathrm{Z} \\
(\mathrm{nT})\end{array}$ & $\begin{array}{c}\mathrm{F} \\
(\mathrm{nT})\end{array}$ & $\begin{array}{c}\mathrm{X} \\
(\mathrm{nT})\end{array}$ & $\begin{array}{c}\mathrm{Y} \\
(\mathrm{nT})\end{array}$ \\
\hline-1.541 & -11.119 & 35593 & -6406 & 33217 & 32581 & -877 \\
\hline
\end{tabular}

3.4 Upward Continuation is considered a clean filter because it produces almost no side effects that may require the application of other filters or processes to correct. Because of this, it is often used to remove or minimize the effects of shallow sources and noise in grids. Also, upward continued data may be interpreted numerically and with modeling programs. This is not the case for many other filter processes. Upward continuation was carried out on the RTE data to depth of $1.5 \mathrm{~km}$. The upward continuation filter operation allows the transformation of potential field data measured on one surface to some higher surfaces [5]. Equation 3 [19] below can be used for the calculation of the upward continuation.

$$
F(x, y,-h)=\frac{h}{2 \pi} \iint \frac{F(x, y, 0) \partial x \partial y}{\sqrt{\left(x-x^{\prime}\right)^{2}+\left(y-y^{\prime}\right)^{2}+h^{2}}}
$$

where, $\mathrm{F}\left(\chi^{\prime}, \mathrm{y}^{\prime},-\mathrm{h}\right)$ is the total field at the point $\mathrm{P}\left(\chi^{\prime}, \mathrm{y}^{\prime}\right.$, $h)$ above the surface on which $F\left(\chi^{\prime}, y^{\prime}, 0\right)$ is known, $h$ is the elevation above surface.

3.5 The Tilt-angle Derivative (TDR) and its Horizontal component (HD_TDR) maps were derived from the tilt derivative filter. Mathematically, equation 4 and 5 were used to calculate the tilt-angle and tilt horizontal derivatives respectively, the unit for both are in radians [18].

$T D R=\operatorname{atan}\left(\frac{1 V D T}{H D_{-} T D R}\right)$ 
$H D \_T D R=\sqrt{ }\left(\left(\frac{d T}{d x}\right)+\left(\frac{d T}{d y}\right)\right)$

where

$1 \mathrm{VDT}=$ first vertical derivative in $\mathrm{z}$-direction

$\mathrm{dT} / \mathrm{dx}=$ derivative in $\mathrm{x}$-direction

$\mathrm{dT} / \mathrm{dy}=$ derivative in $\mathrm{y}$ - direction

3.6 Radially Average Power Spectrum (RAPS) of magnetic data are expressed as function of wavenumber [20]. The spectral analysis is the process of calculating and interpreting the spectrum of the potential field data to derive depth to certain geological features. The spectral depth method is based on the principle that a magnetic field measured at the surface can be considered as an integral of magnetic signature from all depths [21]. RAPS was run for depth to magnetic sources estimations. The power spectrum of a surface field can be used to identify average but maximum depth of source ensemble [22]. The frequency unit is in radians per kilometer (i.e. radians per unit distance). It is necessary to define the power spectrum of a magnetic anomaly in relation to the average depth of the disturbing interface.

Thus, the average depth of burial of the ensemble can be estimated from equation 6 .

$\mathrm{z}=-\mathrm{m} / 2$

Where, $\mathrm{m}$ is the slope of the best fitting straight line. If, however, the frequency unit is in cycles per kilometer, the corresponding relation can be expressed as

$\mathrm{z}=-\mathrm{m} / 4 \pi$
The spectral analysis method is suitable in providing the average depth value to the top of statistical ensemble of blocks of anomalous bodies. These anomalous sources can be interpreted in terms of subsurface structures. The depth to top of geological sources that produced the observed magnetic anomalies in the TMI map of the study area was determined using spectral analysis.

The maps were qualitatively and quantitatively interpreted. The qualitative interpretation was done by inspecting the maps for magnetic variations and signatures (anomalous zones) that are diagnostic of some target points.

\section{RESULTS AND INTERPRETATION}

The magnetic maps were interpreted to deduce range of magnetic intensity of different geologic materials for both crystalline and infilled from weathering, anomaly trends and closures, structures with depths and area with high and low magnetic susceptibilities. The amplitude of a magnetic anomaly is directly proportional to magnetization which depends on magnetic susceptibility of the rocks. Close to the earth's equator (points of low magnetic equator) low susceptible magnetic features appear as high magnetic anomalies and vice versa [23].

The TMI map reveals the magnetic intensity distribution over the study area represented by low/negative and high/positive magnetic anomalies. The total magnetic intensity map was analyzed and interpreted in an attempt to delineate and characterize the subsurface structures in the area. The shaded colour TMI map (Fig. 2) shows high magnetic susceptible areas in low magnetic values while less magnetic susceptible areas are depicted as high magnetic values. In low latitude magnetic region specifically around the equator of which Nigeria is situated, a low/negative magnetic peak value represents typical anomalous signatures $[24,25]$.

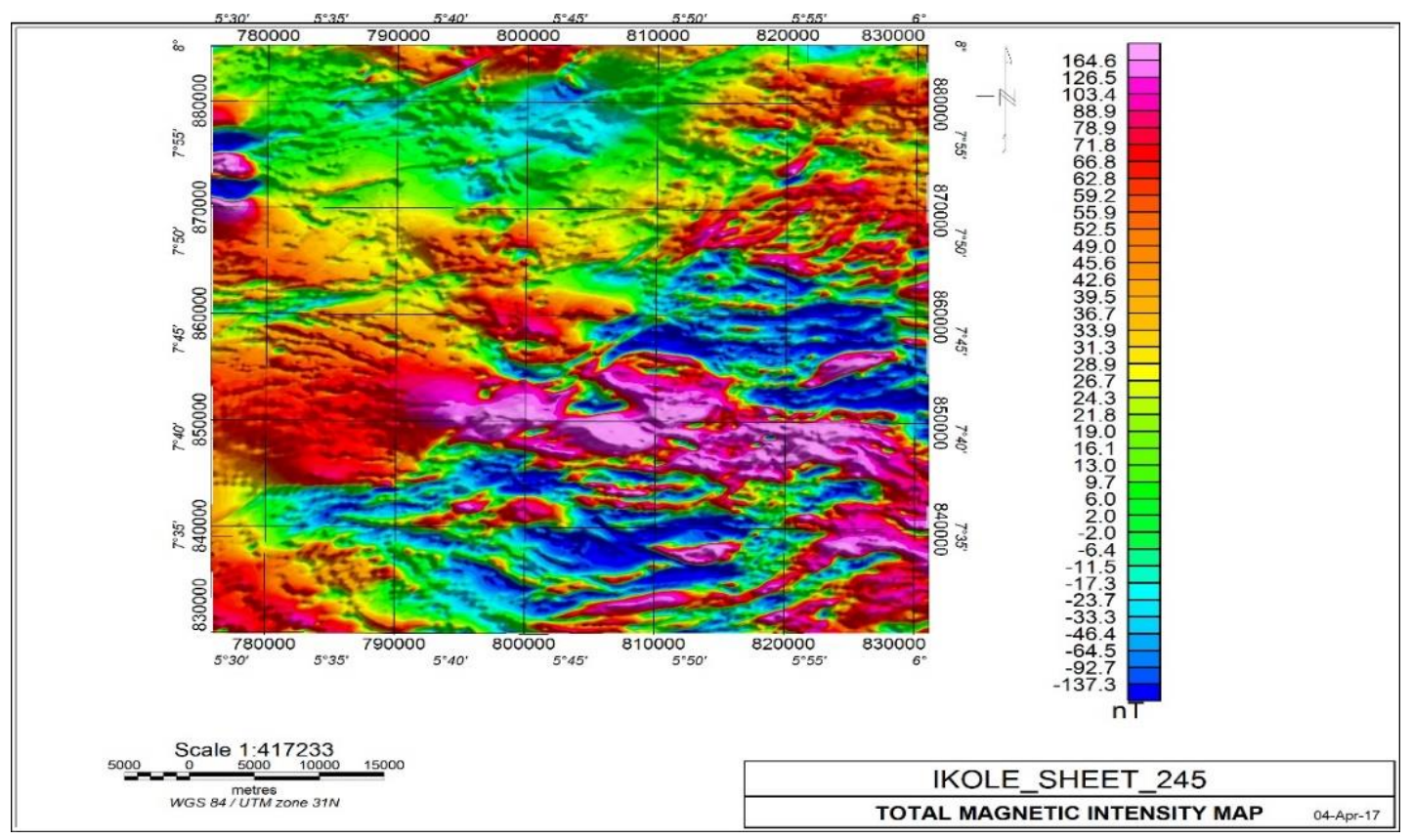

Figure 2. Total magnetic intensity map 


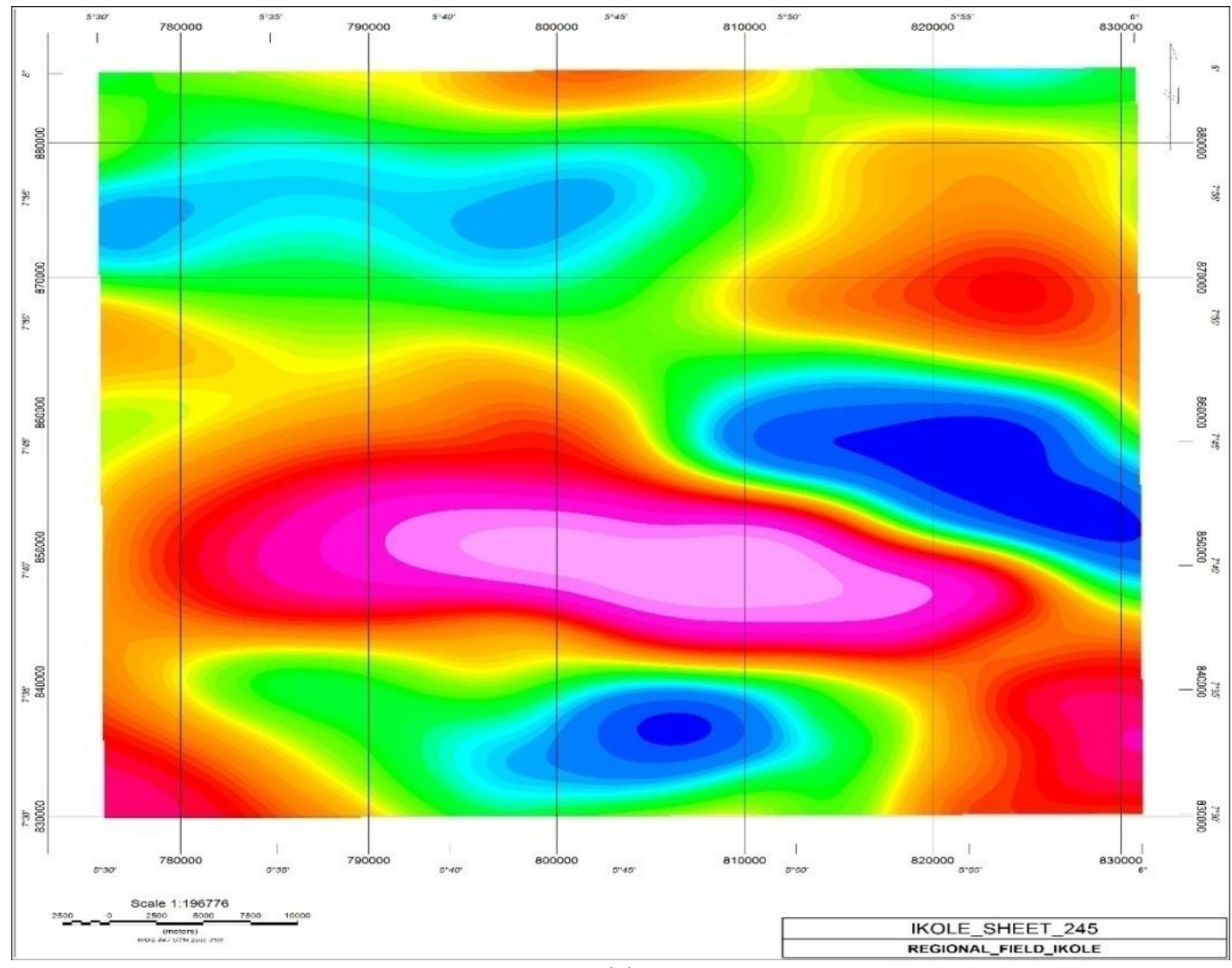

(a)

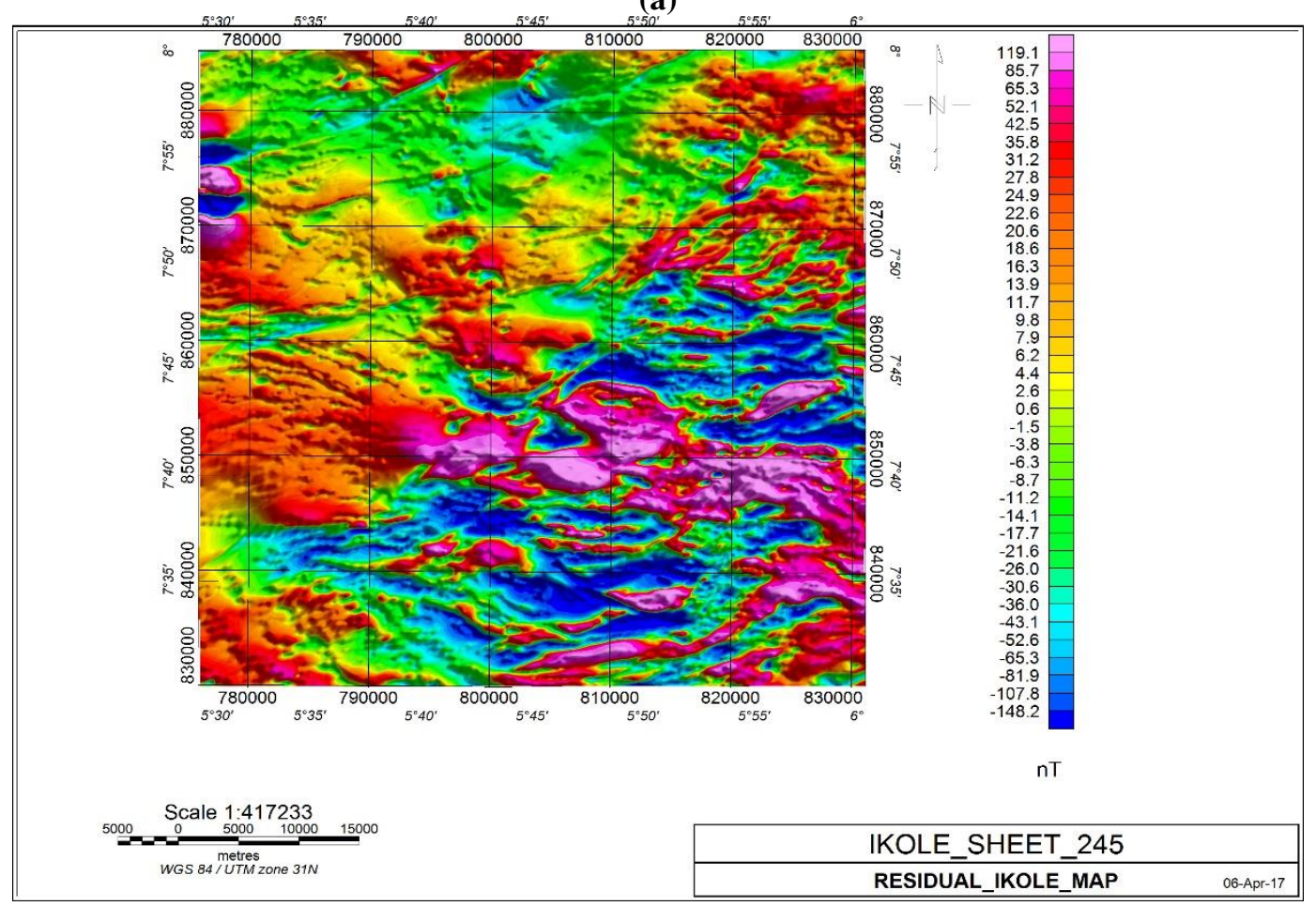

(b)

Figure 3. (a) Regional field map smoothed to a depth of $4 \mathrm{~km}$ and (b) residual map produced from the removal of the regional field from the observed magnetic intensity of the study area

Evaluation of map shows range of intensity variations between -150 and 18 0nT. Areas within $65-18$ 0nT magnetic amplitude range are zone with very high magnetic intensity, 20 - 5 9nT (moderate to high), 2 - 19 nT (Quiet areas with low magnetic amplitudes), and -150 to $-65 \mathrm{nT}$ (very low magnetic amplitudes formed as a result of geological processes that brought about infilled weathered materials and fluid in the rocks). The total magnetic intensity varies from one location to the other due to the mineral contents of both surface and subsurface rocks and level of geological processes; fractures, weathering or retained fluids in those materials. There is a regional lineament trend that runs diagonally from NE-SW dividing the map into equal halves. The southeastern half segment (Akoko axis) has 
pronounced fracturing density and folding, seen as breaks in subtle with a large ridge perpendicular to the lineament trend between two depressions. The ridge between the two depressions is stable and must have outcropped an intruded body due to its high resistive nature to weathering and must have mineral grain compositions different from the surrounding bodies. While, the northwestern half segment (Ikole axis) has several faults both horizontal and vertical (deep seated fault line that runs in N-S direction down to the regional lineament).

Figure 3 shows the Regional field map (left) and the Residual data map (right). The TMI data continued upward to depth of $4 \mathrm{~km}$ produced a regional field assumed to have resulted from relatively deep-seated structures trended in NW-SE direction. The Residual map (Fig. 3, right) is adopted as the real image we are interested in for interpretation, because it gives an undistorted geologic picture of the area with enhanced signal to noise ratio. Clearer image on the general magnetic intensities of the study area is clearly seen on the residual map than what we have on the TMI map because the interfered noise and the regional trends have been removed. The real magnetic intensity ranged in amplitude from -180 to $160 \mathrm{nT}$. The residual map has similar interpretation to what we have in TMI map but obscured features are well pictured.

Reduction to the magnetic equator (RTE) (Fig. 4) is used in low magnetic latitudes to centre the peaks of magnetic anomalies over their sources. This can make the data easier to interpret while not losing any geophysical meaning. Reducing the data to the magnetic pole (RTP) does much the same thing, but at low latitudes, a separate amplitude correction is usually required to prevent North-South signal in the data from dominating the results. As a result, reduced to the pole data may present a less 'honest' view of the data. Reduction to equator gives a better result without losing any geophysical meaning [18]. The high magnetic anomalies are majorly observed in the south-eastern half below the lineament running diagonally relative to the fairly stable north-western part of the lineament. The rocks of low intensities are thought to be highly metamorphosed and weathered rocks comprising migmatite rocks (majorly gneisses and other minor rock types) with large numbers of intrusives such as the central ridge between the two depressions trending in NW-SE direction within Akoko complex (Ondo State). While, the northwestern part (Ikole complex of Ekiti State) above the regional lineament trend of the map showed moderate to low magnetic anomalies, thought to be associated with less weathering, migmatite rocks and other geological processes.

Upward continuation is also useful in the interpretation of magnetic anomaly fields over areas containing many near surface magnetic sources such as dykes and other intrusions by attenuating the high wave number anomalies associated with such features. It enhances relatively the anomalies of the deeper seated sources, hence accentuating the response from basement rocks [26]. Upward continuation maps (Figures 5a and $5 \mathrm{~b}$ (grey)) have been able to give a clearer interpretation to the deep-seated structures in the basement rocks by showing a kind of cascaded structures formed as a result high fracturing and weathering of the rocks in the southern axis of the map. It is evident on the map that rocks in the northern to western segment above the lineament are different in compositions and the basement tends to be more crystalline. On other hand, both maps confirmed different episodes of metamorphism that have restructured the rocks to their present forms seen during reconnaissance mapping and the geological processes tend to be pronounced down depth on regional trend. The fault line is also clearly seen on both maps.

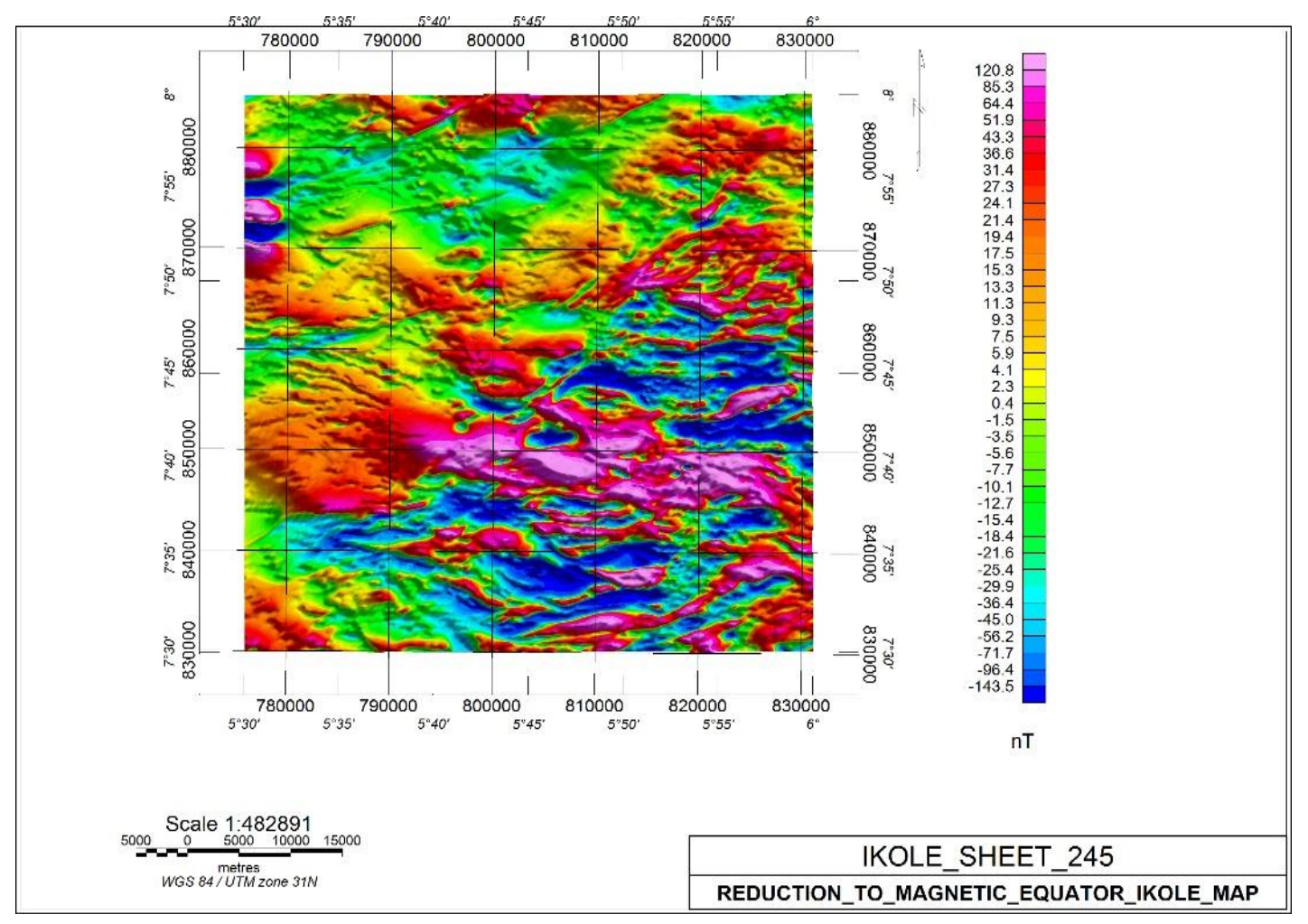

Figure 4. Reduction to magnetic equator map 


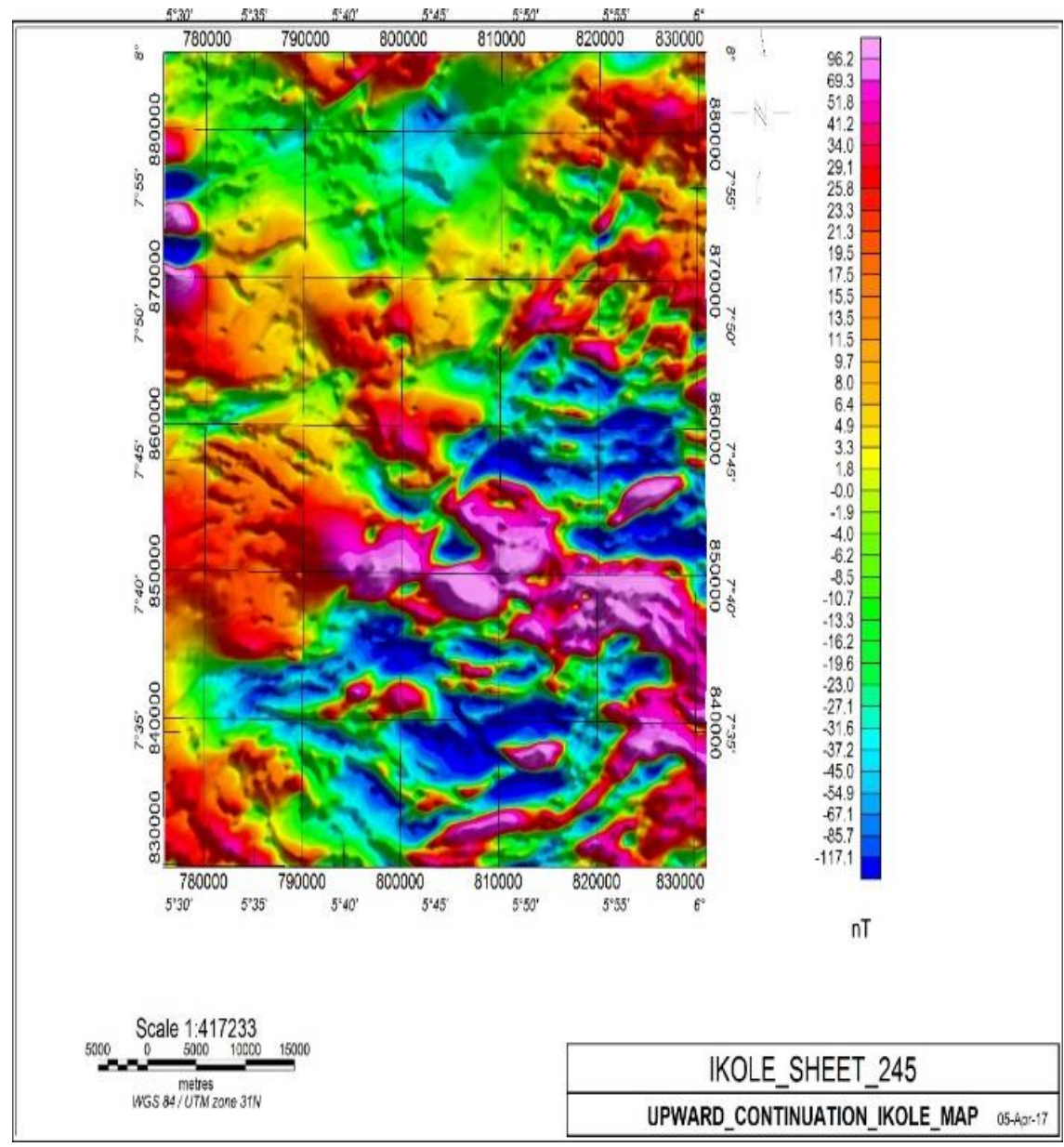

(a)
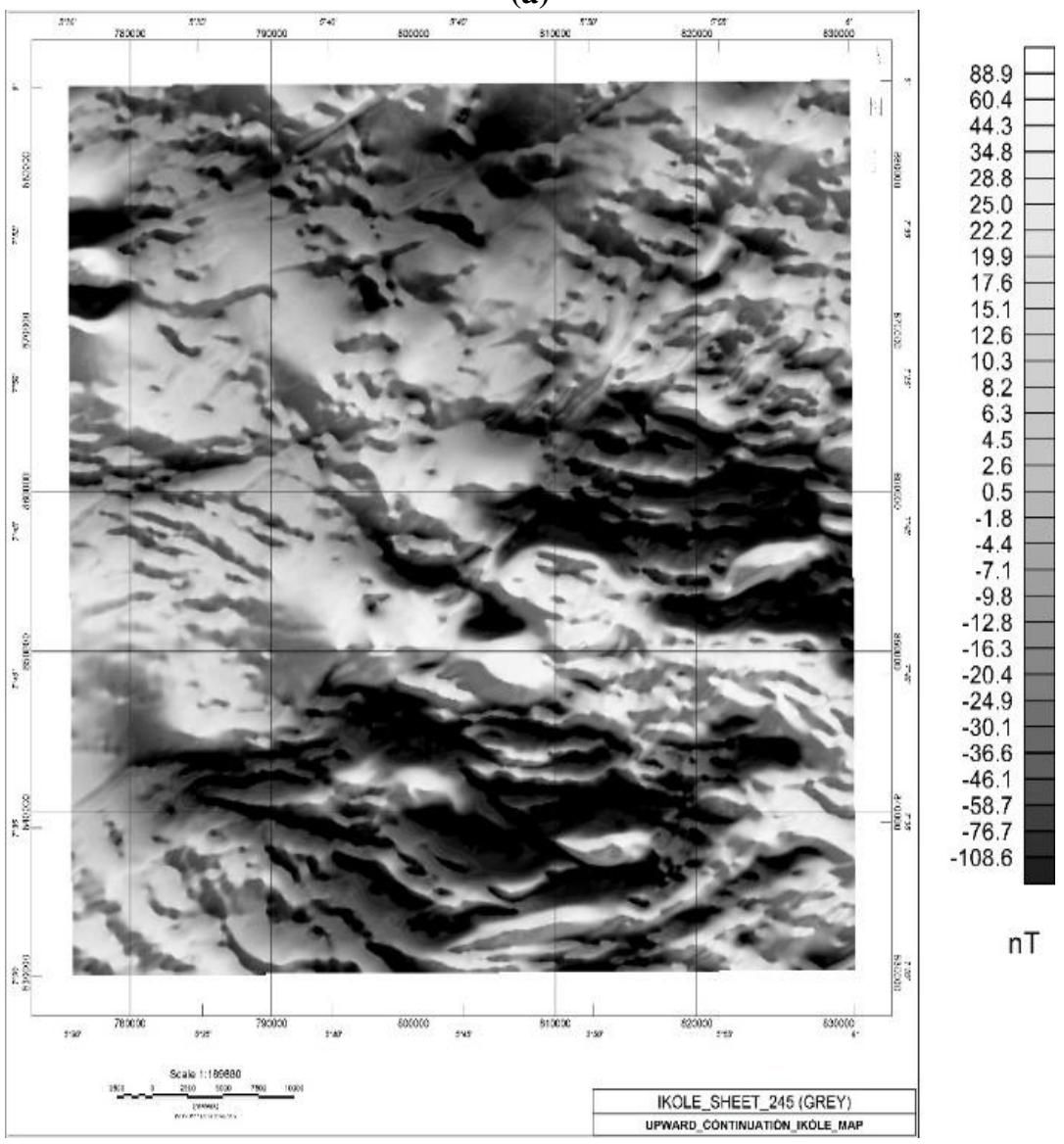

(b)

Figure 5. The Upward Continuation Maps; (a) coloured and (b) Grey for better pictorial and vivid clarifications 
The Tilt-angle Derivative (TDR) and its Horizontal component (HD_TDR) maps of the study area (Figs. 6a and 6b) were derived from the tilt derivative filter applied to determine structures (faults and folds), the contacts and edges or boundaries of magnetic sources, and to enhance both weak and strong magnetic anomalies of the area placing an anomaly directly over its source, especially at shallow depths by using the theory that the zero contours are the edges of the formation [27]. It is observed that the zero contours (yellowish colour) estimate the location of abrupt changes in magnetic susceptibility values, areas which show the lineaments are those with blue colour, while those with red are the undeformed or unweathered basement ranging from -
$1.5-1.5$ radians. The results generated were used to delineate geological structures like faults, folds, lineaments, etc. in the study area. The Ikole axis showed about four faults $(\mathrm{F}-\mathrm{F}$ '), delineated with black lines and a regional lineament trends $\left(\mathrm{R}-\mathrm{R}^{\prime}\right)$, delineated with yellow line that differentiates the geology of the Akoko areas from the Ikole areas. It could be inferred that geological activities have contributed to the fracturing density and breaks in subtle of the underlying geology. It is evident that the earlier delineated structural trends on the TMI maps have similar trends of NE-SW and NW-SE which are perpendicular to the strike direction of the rocks.

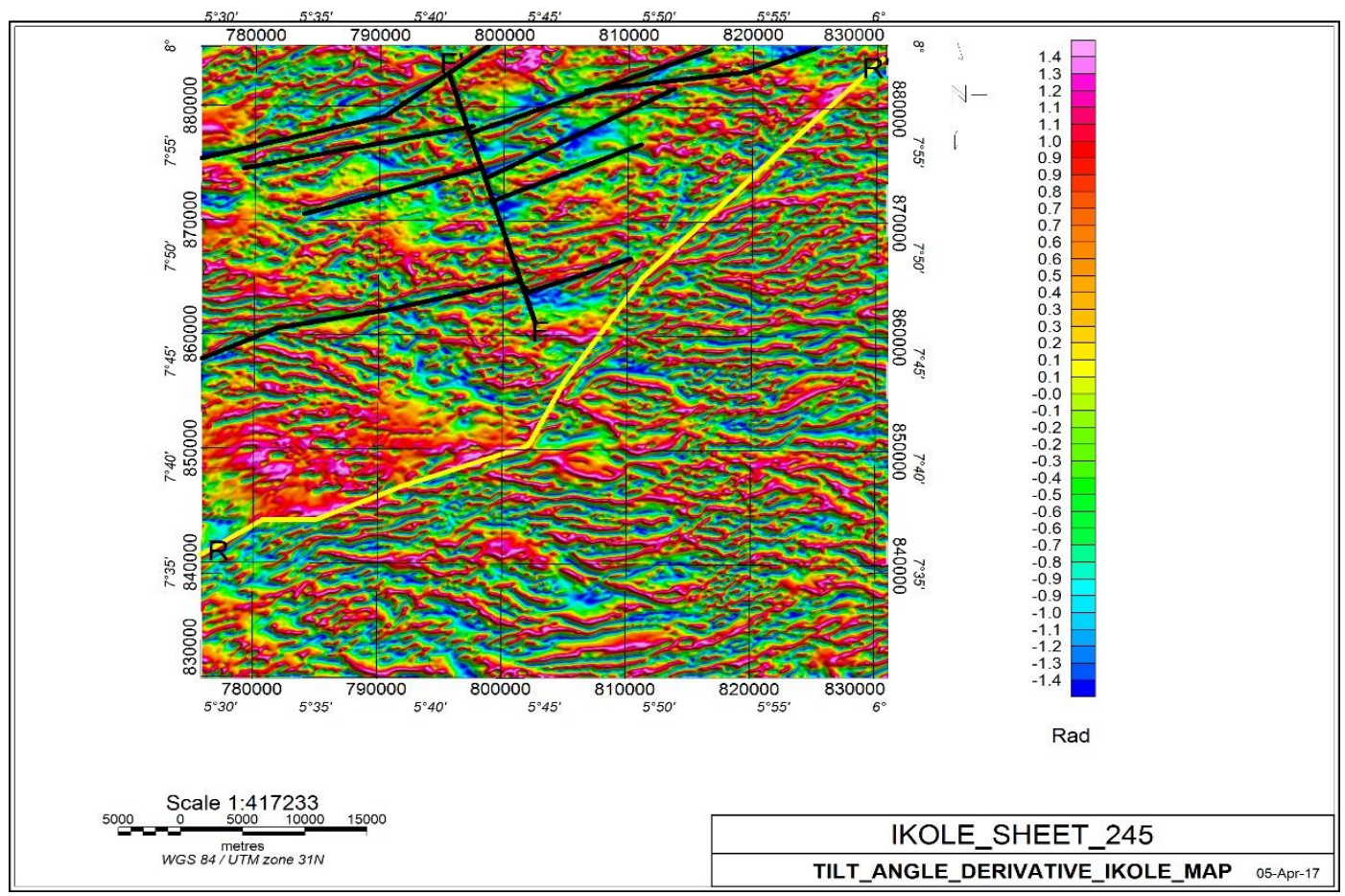

(a)

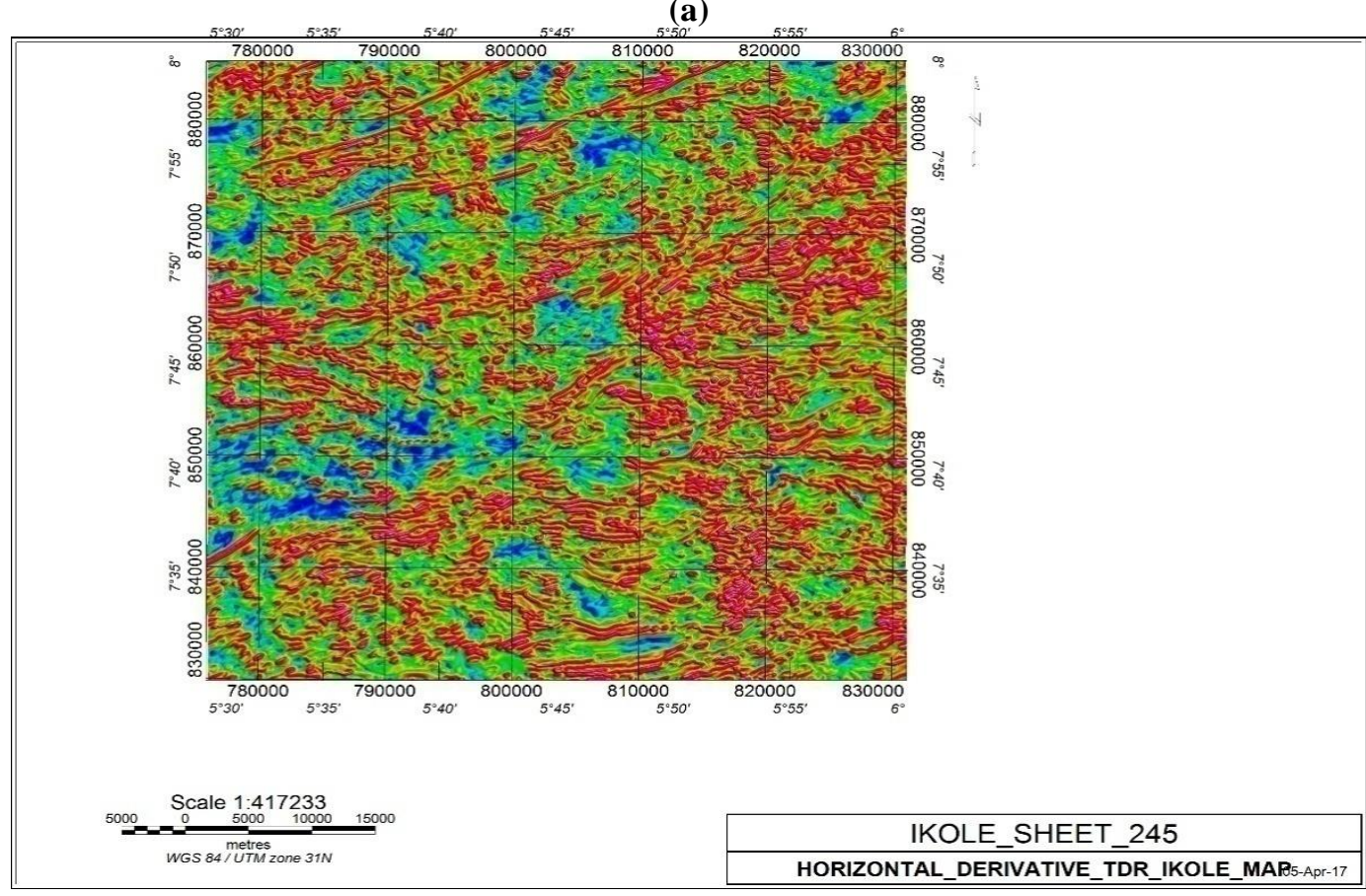

(b)

Figure 6. (a) Tilt-angle Derivative (TDR) (left) and (b) Horizontal Component (right) 


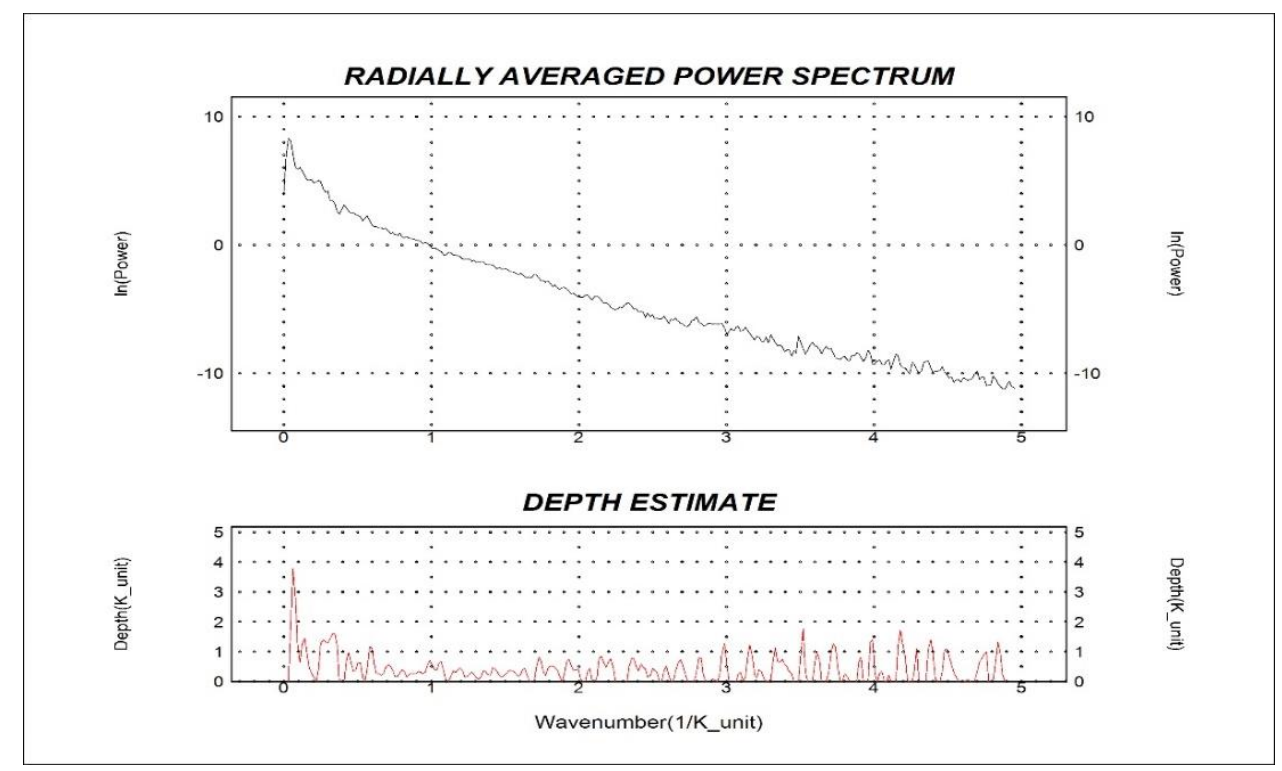

Figure 7. Radially Averaged Power Spectrum (RAPS) for depth estimation

The Radially Averaged Power Spectrum (RAPS) (Fig.7) showed the total depth estimate to the top of magnetic sources that produced the observed anomalies in the study area using spectral analysis. The gradient of the layers were calculated based on the wavelength of the magnetic sources. The gradients are: shallower layer (-1.75) and deeper layer ($20.0)$ with approximate depth estimate of $0.14 \mathrm{~km}$ and 1.60 $\mathrm{km}$ respectively. The total depth estimates from the centre grid ranges from shallower sources $(140 \mathrm{~m})$ to deeper sources $(1.6 \mathrm{~km})$. The source that account for the shallow source depth derived from the statistical spectral analysis could be the effect of outcropping basement rocks of the study area. The deep sources characterized by high negative anomaly values have longer wavelength and could be attributed to the magnetic rocks that intruded the basement and intra-basement features like fractures and faults.

\section{CONCLUSION}

Aeromagnetic interpretation of Ikole Sheet 245 has shown the robust applicability of this method in characterizing magnetic intensities; effective mapping of lithologies and geological structures with their trends, and depth to magnetic sources through the use of various form of filtering and reductions to have a better pictorial view of the subsurface beyond surface expressions. The maps revealed the range of magnetic intensities of various rocks with infilled geologic materials; structural trend ( $\mathrm{N}-\mathrm{S}$ direction), a regional lineament trending $\mathrm{NE}-\mathrm{SW}$, and areas with varying magnetic susceptibility based on intensity amplitude variations. The varying magnetic intensity suggests varying magnetic materials associated with the rock types in the area.

Based on this high resolution aeromagnetic interpretation, the method has proved useful in mapping the basement structures of the area. Also, one can infer that the geology of the study area is different. Ikole basement rocks are quite different from their counterparts in Akoko axis and Kabba axis based on rate of weathering, faulting, magnetic minerals and metamorphism that have restructured the rock types of the study area to their present forms. The result of this study would serve as information framework that would guide the siting of productive boreholes/water wells, rapid selection of targeted areas for mineral exploration, reduction in survey costs and prevention of incessant failure of engineering construction works.

\section{ACKNOWLEDGEMENT}

The author appreciates the Nigerian Geological Survey Agency, Abuja Nigeria for providing the aeromagnetic data for this research work.

\section{REFERENCES}

[1] Carmichael R.S. (1989). Practical Handbook of Physical Properties of Rocks and Minerals, Boca Raton, Ann Arbor, CRC Press, Boston.

[2] Physical properties of rocks: Fundamentals and principle of petrophysics, (1996). Schon J.H., Klaus H., Sven T. (Eds), Pergamon Press, London, p. 583.

[3] Lowrie W. (2007). Fundamental of Geophysics, Low Price Paper Back Edition, Cambridge University Press, Cambridge. pp. 229-306.

[4] Akanbi E.S., Fakoya A.D. (2015). Regional magnetic field trend and depth to magnetic source determination from aeromagnetic data of Maijuju Area, North Central, Nigeriar Physical Science International Journal, Vol. 8, No. 3, pp. 1-13. DOI: $\underline{10.9734 / \mathrm{PSIJ} / 2015 / 21652}$

[5] Nabighian M.N., Grauch V.J.S., Hansen R.O., LaFehr T.R., Li Y., Peirce J.W., Phillips J.D., Ruder M.E. (2005). The historical development of the magnetic method in exploration, Geophysics, Vol. 70, pp. 33-61. DOI: $10.1190 / 1.2133784$

[6] Armstrong M., Rodeghiero A. (2006). Airborne geophysical techniques in Aziz, Coal Operators' Conference, University of Wollongong and the Australasian Institute Mining and Metallurgy, pp. 113131.

[7] Oyawoye M.O. (1972). The basement complex of Nigeria, In African Geology, Dessauvagie T.F.J., 
Whiteman A.J. (Eds), Ibadan University Press, pp. 6799.

[8] Rahaman M.A. (1981). Recent advances in the study of the basement complex of Nigeria, First Symposium on the Precambrian Geology of Nigeria, Summary.

[9] Woakes M., Ajibade C.A., Rahaman M.A. (1987). Some metallogenic features of the Nigerian Basement, Journal of Africa Science, Vol. 5, pp. 655-664.

[10] Ajibade A.C., Fitches W.R. (1988). The Nigerian Precambrian and the Pan -African Orogeny, Precambrian Geology of Nigeria, pp. 45-53.

[11] Oyinloye A.O. (2011). Geology and geotectonic setting of the basement complex rocks in southwestern Nigeria: Implications on provenance and evolution, Earth and Environmental Sciences, pp. 98-117.

[12] Rahaman M.A., Emofurieta W.O., Cean-Vachette M. (1983). The potassic granite of Igbetti area. Further evidence of the polycyclic evolution of the PanAfrican belt in Southwestern Nigeria, Journal of Precambrian Resources, Vol. 22, pp. 75-92.

[13] Ajibade A.C., Woakes M., Rahaman M.A. (1987). Proterozoic crustal development in Pan-African regime of Nigeria: In A. Croner (ed.), Proterozoic Lithospheric Evolution Geodynamics, Vol. 17, pp. 259-231.

[14] Jones H., Hockey R. (1964). Geology of parts of southwestern Nigeria, Geological Survey of Nigeria Bulletin, No. 31.

[15] Nigerian Geological Survey Agency (NGSA), (2009). Geological map of Nigeria, Map prepared by Nigerian Geological Survey Agency. 31, Shetima Mangono Crescent Utako District, Garki, Abuja.

[16] Briggs I.C. (1974). Machine contouring using minimum curvature, Geophysics, Vol. 39, pp. 39-48.

[17] Leu L.K. (1981). Use of reduction-to-equator process for magnetic data interpretation: Presented at the 51st
Ann, Internat. Mtg., Sot. Exnl. Geonhv, Geophysics, Vol. 47, p. 445.

[18] Oasis Montaj ${ }^{\mathrm{TM}}$ Tutorial, (2004). Two - Dimensional frequency domain processing of potential field data.

[19] Telford W.M., Geldart L.P., Sheriff R.E., Keys D.A. (1990). Applied Geophysics, $2^{\text {nd }}$ edition, Cambridge University Press, Cambridge.

[20] Blanco-Montenegro I., Torta J.M., Garcia A., Arana V. (2003). Analysis and modeling of the aeromagnetic anomalies of Gran Canaria (Canary Islands), Earth and Planetary Science Letters, Vol. 206, pp. 601-616. DOI: $\underline{10.1016 / \mathrm{S} 00128821 \mathrm{X}(02) 01129-9}$

[21] Rabeh T. (2009). Prospecting for the ferromagnetic mineral accumulations using the magnetic method at the Eastern Desert, Egypt, Geophysical Engineering, Vol. 6, pp. 401-411. DOI: $\underline{10.1088 / 1742-2132 / 6 / 4 / 008}$

[22] Spector A., Grant F. (1970). Statistical models for interpreting aeromagnetic data, Geophysics, Vol. 35, pp. 293-302.

[23] Gunn P.J., Maidment D., Milligan P.R. (1997). Interpreting magnetic data in areas of limited outcrop, AGSO Journal of Australian Geology and Geophysics, Vol. 17, No. 2, pp. 175-185.

[24] Parasnis D.S. (1996). Principles of applied geophysics, 5th ed. Chapman Hall, London, p. 456.

[25] Fieberg F.C. (2002). Ground magnetic investigations for gold prospecting in Southwestern Nigeria, Presentation given at the 62nd Meeting of the German Geophysical Society, Hannover.

[26] Kearey P., Brooks M., Hill I. (2002). An Introduction to Geophysical Exploration. $3^{\text {rd }}$ ed, Oxford: Blackwell Science, p. 262.

[27] Salem A., Williams S., Fairhead J., Ravat D., Smith R. (2007). Tilt-depth method: a simple depth estimation method using first-order magnetic derivatives, The Leading Edge, Vol. 26, pp. 1502-1505. DOI: $\underline{10.1190 / 1.2821934}$ 